\title{
SIMO Transadmittance Mode Active-C Universal Filter
}

\author{
Neeta Pandey ${ }^{1}$, Sajal K. Paul ${ }^{2 *}$ \\ ${ }^{1}$ Department of Electronics and Communications, Delhi Technological University, Delhi, India \\ ${ }^{2}$ Department of Electronics and Instrumentation, Indian School of Mines, Dhanbad, India \\ E-mail: \{n66pandey, sajalkpaul\}@rediffmail.com \\ Received August 6, 2010; revised September 10, 2010; accepted September 13, 2010
}

\begin{abstract}
This paper presents two transadmittance mode universal filters having single voltage input and multiple current outputs. The filter employs three multiple output current controlled conveyors (MOCCCII) and two grounded capacitors. It can realize low pass, high pass, band pass, notch and all pass responses. As desired, the input voltage signal is inserted at high impedance input terminal and the output currents are obtained at high impedance output terminals and hence eases cascadability. The filter enjoys low sensitivity performance and low component spread; and exhibits electronic and orthogonal tunability of filter parameters via bias currents of MOCCCII. SPICE simulation results confirm the workability of the proposed structure.
\end{abstract}

Keywords: Universal Filter, Transadmittance Mode, Current Controlled Conveyor

\section{Introduction}

There has been substantial emphasis on development of current conveyor based filters in the recent past which can be attributed to its high performance properties such as wider signal bandwidths, greater linearity, larger dynamic range, lower power consumption, simple circuitry and occupy lesser chip area than their voltage mode counterparts [1]. The filters employing operational transconductance amplifier (OTA) possess lower dynamic range with power supply scaling as its input are voltage dependent. The need for lower power consumption requires low bias current and hence lower output current [2]. The OTA requires bias current of four times the current needed by current controlled conveyor (CCCII) [3] for the same transconductance. Thus circuits based on CCCII consume lesser power than OTA based circuits. The maximum usable frequency range depends strongly on bias current, hence high frequency response of CCCII based implementations are expected to be better than OTA. Already a number of voltage and current mode filter structures based on current conveyor have been reported in the literature [3-13] and references cited therein. A voltage-mode (VM) circuit is one whose signal states are computed as node voltages while a currentmode $(\mathrm{CM})$ circuit is one whose signal states defined by its branch currents. In some applications there is need of filtering a voltage signal and then converting it to current signal by using a voltage to current converter $(\mathrm{V} \rightarrow \mathrm{I})$ interfacing circuit. The total effectiveness of the electronic circuitry can be increased if signal processing can be combined with $\mathrm{V} \rightarrow \mathrm{I}$ interfacing. A transadmittance mode filter is suitable for such applications and finds usage in receiver base band blocks of modern radio system [14]. A careful study indicates that a limited literature is available on transadmittance mode filter [14-18]. These circuits can nicely perform the operation of transadmittance mode filter, but still there is scope to improve them in the following fronts: use of floating passive components [14-18] which is not considered good for IC implementation point of view; input voltages are not applied at high impedance terminal $[14,16,18]$; availability of output currents through passive components [17] thus there is requirement of additional hardware; and filter parameters are not electronically tunable [17]. It thus reveals that no literature is available on transadmittance mode universal filter that can simultaneously possess the following advantageous features: 1) use of all grounded passive components, 2) high impedance terminal for input excitation, 3) output at high impedance and 4) electronic tunability of filter parameters.

In this work, two current controlled conveyor based transadmittance mode universal filter circuits are proposed based on [10-13] that use only three MOCCCIIs and two grounded capacitors. The first structure provides band pass, high pass and notch responses simultaneously and all pass and low pass responses can be obtained by connecting together appropriate outputs. The low pass, 
band pass, high pass and notch responses are simultaneously available in the second proposed structure and all pass response can be obtained by connecting together suitable outputs. As desired, in both the structures, the input voltage signal is inserted at high impedance input terminal and the output currents are obtained at high impedance output terminals. The filter parameters are adjustable through bias currents of MOCCCII. The filter, under all operations, exhibits low active and passive sensitivities. The function of the proposed structure has been confirmed by SPICE simulations.

\section{Circuit Description}

The port relationships of a MOCCCII as shown in Figure 1 can be characterized by

$$
v_{X}=v_{Y}+i_{X}\left|R_{X}\left(I_{0}\right)\right|, \quad i_{Y}=0, \quad i_{Z \pm}= \pm i_{X}
$$

where the positive and negative signs denote the positive and negative current transfers. $R_{x}$ is the input resistance at x port which can be controlled via bias current $I_{0}$ [3]. The MOCCCII can be realized using bipolar transistor or CMOS (Figure 2), the value of $R_{x}$ is given as $R_{X}=V_{T} / 2 I_{0}$ for bipolar realization or MOS transistors operating in weak inversion region, where $V_{T}$ is the thermal voltage; whereas $R_{X}=1 /\left(g_{m 2}+g_{m 4}\right)$ for MOS transistors operating in strong inversion [19], where $g_{m i}=\sqrt{2 \mu_{i} C_{o x}\left(W_{i} / L_{i}\right) I_{0}}$.

The first proposed transadmittance mode universal filter is shown in Figure 3, which employs three MOCCCIIs and two grounded capacitors. The routine analysis of the circuit yields the following transfer functions:

$$
\begin{gathered}
\frac{I_{\text {out } 1}}{V_{\text {in }}}=-\frac{1}{R_{x 1} D(s)}, \frac{I_{\text {out } 2}}{V_{\text {in }}}=\frac{s C_{2} R_{x 2}}{R_{x 1} D(s)}, \\
\frac{I_{\text {out } 3}}{V_{\text {in }}}=-\frac{s^{2} C_{1} C_{2} R_{x 2}}{D(s)}, \frac{I_{\text {out } 4}}{V_{\text {in }}}=\frac{s^{2} C_{1} C_{2} R_{x 1} R_{x 2}+1}{R_{x 1} D(s)}
\end{gathered}
$$

where $\quad D(s)=s^{2} C_{1} C_{2} R_{x 1} R_{x 2}+s C_{2} R_{x 2}+1$

Thus the proposed structure of Figure 3 can be viewed

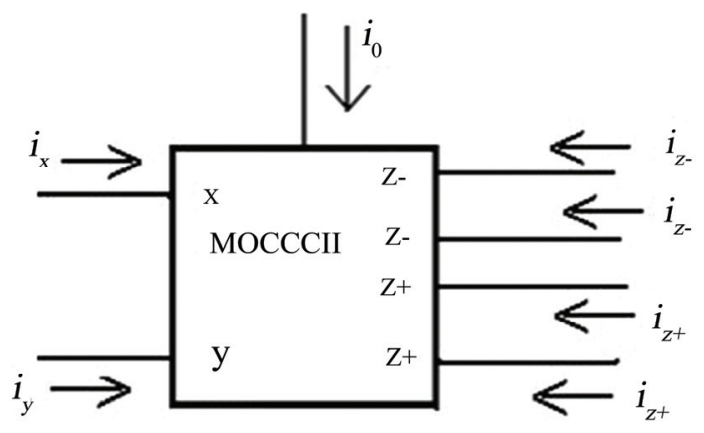

Figure 1. Circuit symbol of MOCCCII.

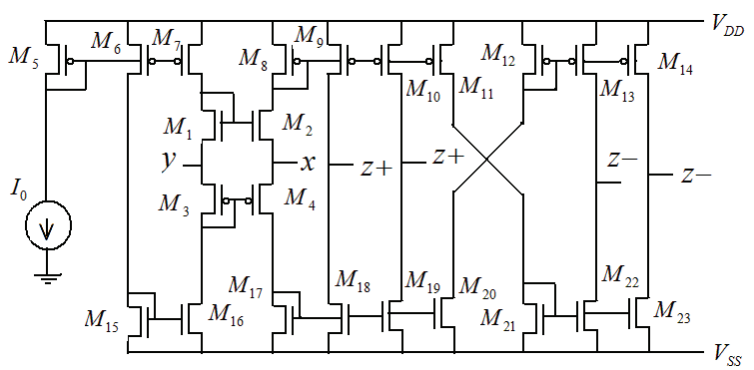

Figure 2. CMOS representation of MOCCCII [19].

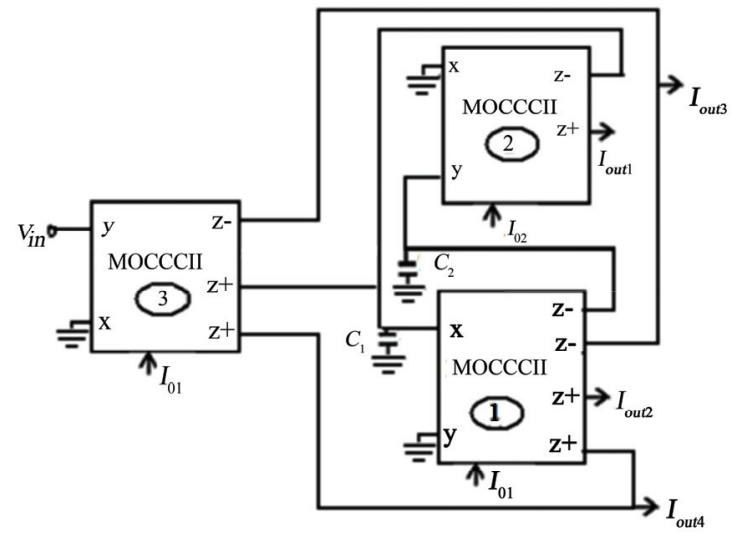

Figure 3. First proposed structure.

as single-input four-output transadmittance mode universal filter. It provides low pass, band pass, high pass and notch responses at $\mathrm{I}_{\text {out } 1}, \mathrm{I}_{\text {out } 2}, \mathrm{I}_{\text {out } 3}$ and $\mathrm{I}_{\text {out } 4}$ respectively. The all pass responses can easily be obtained by adding $\mathrm{I}_{\text {out } 1}, \mathrm{I}_{\text {out } 2}$ and $\mathrm{I}_{\text {out3 }}$. Furthermore, the input voltage is applied at high impedance y-port and all the current outputs are available at high impedance z-port of current controlled conveyors that enable easy cascadability without the need of supplementary buffer circuit.

All the filters are characterized by

$$
\begin{gathered}
\omega_{0}=\left(\frac{1}{R_{x 1} R_{x 2} C_{1} C_{2}}\right)^{1 / 2}, \frac{\omega_{0}}{Q_{0}}=\frac{1}{R_{x 1} C_{1}} \text { and } \\
Q_{0}=\left(\frac{R_{x 1} C_{1}}{R_{x 2} C_{2}}\right)^{1 / 2}
\end{gathered}
$$

It may be noted from (3) that $\omega_{0}$ can be adjusted by varying bias current $\mathrm{I}_{02}$ (or $R_{x 2}$ ) without disturbing $\omega_{0} / Q_{0}$ and similarly $\omega_{0}$ and $Q_{0}$ are orthogonally adjustable with simultaneous adjustment of $\mathrm{I}_{01}$ and $\mathrm{I}_{02}$.

The second proposed structure is shown in Figure 4, which uses two MOCCCIIs and a minus type CCCII and two grounded capacitors. The transfer functions for the circuit of Figure 4 can be expressed as

$$
\frac{I_{\text {out } 1}}{V_{\text {in }}}=\frac{s^{2} C_{1} C_{2} R_{x 2}}{D(s)}, \frac{I_{\text {out } 2}}{V_{\text {in }}}=\frac{s C_{1}}{D(s)}, \frac{I_{\text {out } 3}}{V_{\text {in }}}=\frac{D(s)-s C_{1} R_{x 1}}{R_{x 1} D(s)}
$$




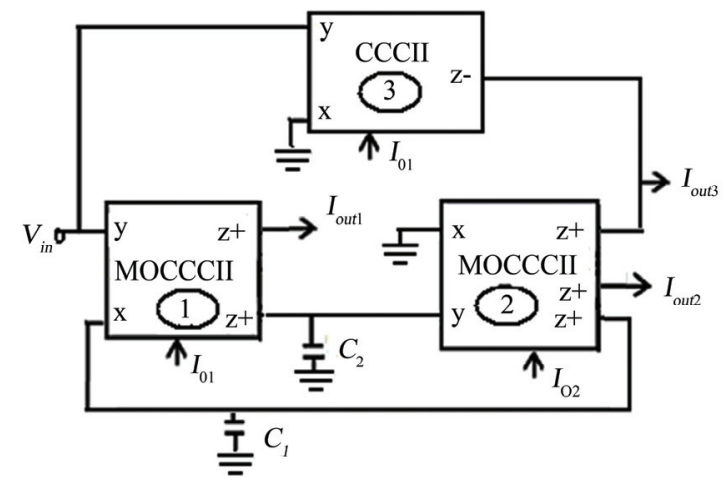

Figure 4. Second proposed structure.

where

$$
D(s)=s^{2} C_{1} C_{2} R_{x 1} R_{x 2}+s C_{2} R_{x 2}+1
$$

Thus the second structure can also be viewed as single-input three-output transadmittance mode universal filter. It provides high pass and band pass responses at $I_{\text {out1 }}$ and $I_{\text {out2 }}$. The notch response is available at $I_{\text {out3 }}$ for equal capacitors $\mathrm{C}_{1}=\mathrm{C}_{2}$ and bias currents $\mathrm{I}_{01}=\mathrm{I}_{02}$. The low pass and all pass responses can easily be obtained by adding $\mathrm{I}_{\text {out } 1}$ and $\mathrm{I}_{\text {out } 3}$; and $\mathrm{I}_{\text {out } 2}$ and $\mathrm{I}_{\text {out3 }}$ respectively. Like the previous one, both the input and output impedances are high for input voltage and output currents respectively.

The results of active and passive sensitivity analysis of various parameters for both the proposed filters are given as

$$
\begin{gathered}
S_{R_{x 1}}^{\omega_{0}}=S_{R_{x 2}}^{\omega_{0}}=S_{C_{1}}^{\omega_{0}}=S_{C_{2}}^{\omega_{0}}=-1 / 2, \\
S_{R_{x 1}}^{Q_{0}}=-S_{R_{x 2}}^{Q_{0}}=S_{C_{1}}^{Q_{0}}=-S_{C_{2}}^{Q_{0}}=1 / 2
\end{gathered}
$$

Hence the sensitivities of pole $\omega_{0}$ and quality factor $Q_{0}$ are low and within unity in magnitude. Thus the propos- ed structure can be classified as insensitive.

The Equation (3) also indicates that high values of $Q$-factor will be obtained from moderate values of ratios of passive components i.e., from low component spread [20]. These ratios can be chosen as $\left(R_{x 1} / R_{x 2}\right)=$ $\left(C_{1} / C_{2}\right)=Q_{0}$. Hence the spread of the component values becomes of the order of $\sqrt{Q_{0}}$. This feature of the filter related to the component spread allows the realization of high $Q_{0}$ values more accurately compares to the topologies where the spread of passive components becomes $Q_{0}$ or $Q_{0}^{2}$.

\section{Comparison}

Table 1 shows the comparison of the present work with the previously reported works [14-18]. The study of Table 1 reveals the following.

1) [14] uses the same number of active components as that of present work, whereas the number of passive components are more in [14] and most of them are floating. Input impedance is low which is not desirable for a circuit having input as voltage signal. The NF and AP responses are not obtainable from this circuit.

2) [15] uses more number of active and passive components than that of the present work and most of the passive components are floating. Input impedance is low and NF and AP responses are not possible as that of [14].

3) Although [16] and [17] use single active component, the number of passive components are more and some of them are floating. [16] has low input impedance and can implement only AP response. [17] can implement only LP and BP responses which are available through passive components, hence requires some more active com-

\begin{tabular}{|c|c|c|c|c|c|}
\hline Ref. & $\begin{array}{l}\text { No. and type of active } \\
\text { components }\end{array}$ & $\begin{array}{l}\text { No. and type } \\
\text { of passive } \\
\text { components }\end{array}$ & $\begin{array}{l}\text { No. of inputs and } \\
\text { input impedance }\end{array}$ & $\begin{array}{l}\text { Possible output responses and } \\
\text { output impedance }\end{array}$ & $\begin{array}{l}\text { Simultaneous } \\
\text { outputs }\end{array}$ \\
\hline [14] & $3 \mathrm{CCII}$ & $\begin{array}{l}2 \text { floating } \mathrm{R} \\
1 \text { grounded } \mathrm{R} \\
2 \text { floating } \mathrm{C}\end{array}$ & $\begin{array}{l}\text { Single, low input } \\
\text { impedance }\end{array}$ & $\begin{array}{l}\text { LP, BP, HP all at high output } \\
\text { impedance; } \\
\text { NF and AP not possible }\end{array}$ & 3 \\
\hline$[15]$ & $\begin{array}{l}3 \text { PFTFN realized } \\
\text { using } 6 \text { CFOA }\end{array}$ & $\begin{array}{l}2 \text { floating } R \\
1 \text { grounded } R \\
2 \text { floating } C\end{array}$ & $\begin{array}{l}\text { Single, low input } \\
\text { impedance }\end{array}$ & $\begin{array}{l}\text { LP, BP, HP all at high output } \\
\text { impedance; } \\
\text { NF and APF not possible }\end{array}$ & 3 \\
\hline [16] & single CCIII & $\begin{array}{l}2 \text { floating } \mathrm{R} \\
1 \text { grounded } \mathrm{R} \\
1 \text { grounded } \mathrm{C}\end{array}$ & $\begin{array}{l}\text { Single, low input } \\
\text { impedance }\end{array}$ & $\begin{array}{l}\text { Only AP response at high output } \\
\text { impedance }\end{array}$ & 1 \\
\hline [17] & Single opamp & $\begin{array}{l}1 \text { floating } R \\
1 \text { grounded } R \\
1 \text { grounded } C\end{array}$ & $\begin{array}{l}\text { Single, high input } \\
\text { impedance }\end{array}$ & $\begin{array}{l}\text { LP and BP output Current through } \\
\text { passive components; HP, AP, NF } \\
\text { not possible }\end{array}$ & 2 \\
\hline$[18]$ & 2CDTA & $\begin{array}{l}2 \text { floating } \mathrm{R} \\
1 \text { floating } \mathrm{C} \\
1 \text { grounded } \mathrm{C}\end{array}$ & $\begin{array}{l}\text { Three, low input } \\
\text { impedance }\end{array}$ & $\begin{array}{l}\mathrm{LP}, \mathrm{HP}, \mathrm{BP}, \mathrm{AP}, \mathrm{NF} \text { all at high } \\
\text { output impedance }\end{array}$ & 1 \\
\hline $\begin{array}{l}\text { Present } \\
\text { work }\end{array}$ & $3 \mathrm{CCCII}$ & 2 grounded C & $\begin{array}{l}\text { Single, high input } \\
\text { impedance }\end{array}$ & $\begin{array}{c}\text { LP, HP, BP, AP, NF all at high } \\
\text { output impedance }\end{array}$ & $4 \& 3$ \\
\hline
\end{tabular}
ponents (opamps, $\mathrm{CC}$ etc.) to use these responses.

Table 1. Comparison of the present work with the previously reported works. 
4) [18] is a good proposition which uses only two active components and implements all responses of universal filter. However, it suffers form the drawback of using excessive numbers of passive components and most of them are floating and also input impedance is low which is not desirable for a transadmittace mode filter.

Hence it reveals that the present work removes most of the drawback which were prevailing in transadmittance mode universal filter reported till date.

\section{Simulation Results}

To validate the theoretical predictions, the proposed filter is simulated with SPICE using schematic of MOCCCII as given in Figure 2 [19] using AMS 0.35 $\mu \mathrm{m}$ CMOS technology with dimensions of the NMOS and PMOS transistors as that of [19] and supply voltages of \pm 1.5 volts. Figure 5 shows the simulation results for circuit of Figure 3 with the component values of $\mathrm{C}_{1}=\mathrm{C}_{2}=10 \mathrm{pF}$ and $\mathrm{I}_{01}=\mathrm{I}_{02}=100 \mu \mathrm{A}$. The total power dissipation of the proposed filter is found to be approximately $10 \mathrm{~mW}$.

The simulations have also been carried out to show the dependence of $f_{0}$ on bias current and results are shown in Figure 6 for band pass response. It is found that $f_{0}$ depends linearly for low bias currents whereas for higher bias current the dependence is approximately proportional to the square root of the bias current. The percentage total harmonic distortion (\%THD) variation with the sinusoidal input signal is also studied and the results are shown in Figure 7. It shows that the \%THD is low and remains within the acceptable limit of 5\% [21] till the considerable high input signal of $800 \mathrm{mV}$.

\section{Conclusions}

Two new single-input mutiple-output transadmittance

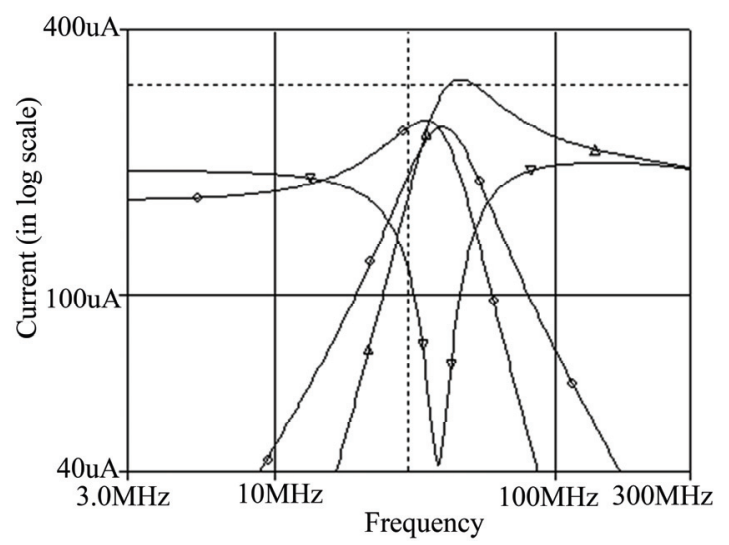

Figure 5. Simulated results for low pass, band pass, high pass and notch responses.
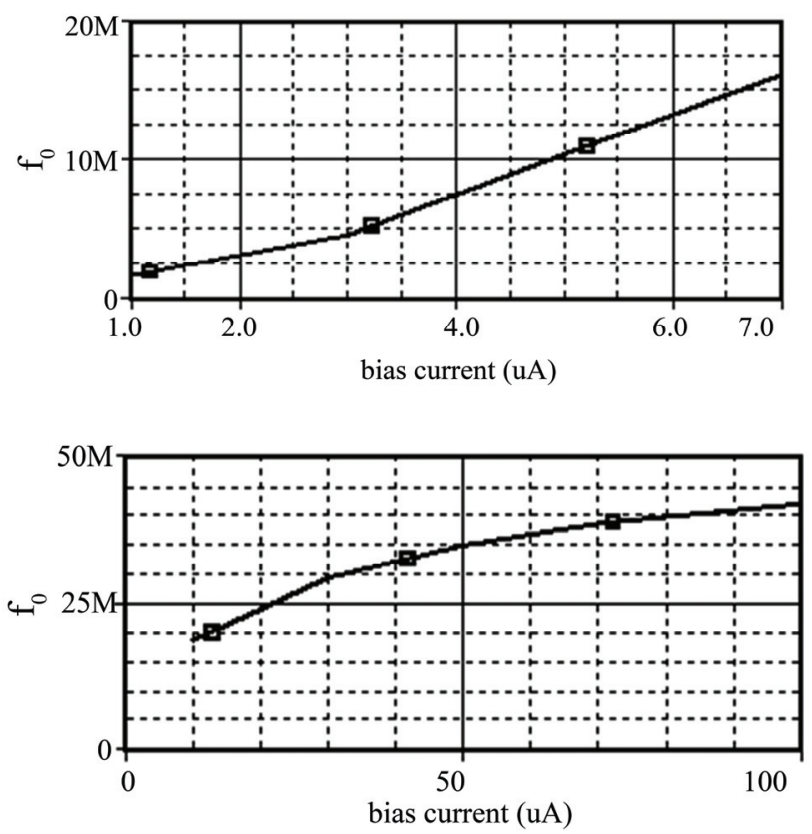

Figure 6. Dependence of central frequency on bias current.

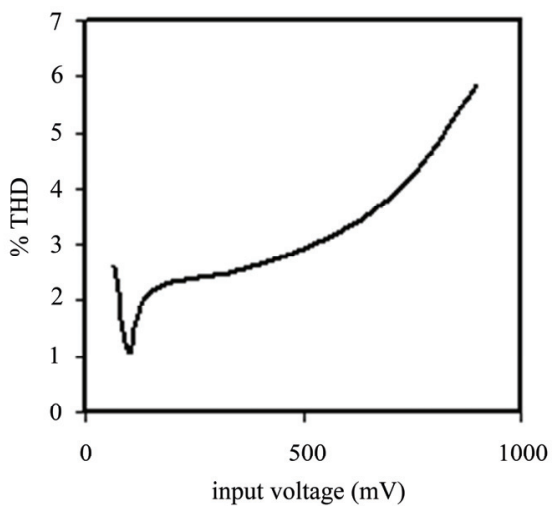

Figure 7. Variation of THD with input signal amplitude.

mode universal filters using three MOCCCII and two grounded capacitors have been presented. The simulation results verify the theory. It is found from the comparison that the present work removes most of the drawback of the previously reported works [14-18]. The salient features of the proposed circuits are as follows: use of only three MOCCCIIs and two capacitors, uses grounded passive components, low sensitivity performance, orthogonal and electronic tunability of $\omega_{0}$ and $Q_{0}$, high input and output impedances which ease cascadability and low component spread for high $Q$ application.

\section{References}

[1] G. Ferri and N. C. Guerrini, "Low-Voltage Low-Power CMOS Current Conveyors," Kluwer Academic Publishers, London, 2003. 
[2] N. A. Shah, M. F. Rather and S. Z. Iqbal, "Multifunction Mixed Mode Filter Using FTFN," Analog Integrated Circuits and Signal Processing, Vol. 47, No. 3, 2006, pp. 339-343.

[3] A. Fabre, O. Saaid, F. Wiest and C. Boucheron, "High Frequency Applications Based on a New Current Controlled Conveyor," IEEE Transactions on Circuits Systems-I, Vol. 43, No. 2, 1996, pp. 82-91.

[4] N. Pandey, S. K. Paul and S. B. Jain, "A New Electronically Tunable Current Mode Universal Filter Using MOCCCII," Analog Integrated Circuits and Signal Processing, Vol. 58, No. 2, 2009, pp. 171-178.

[5] S. Ozoguz, A. Toker and O. Cicekoglu, "New CurrentMode Universal Filters Using Only CCII + s," Microelectronics Journal, Vol. 30, No. 3, 1999, pp. 255-258.

[6] W. Tangsrirat, "Current Tunable Current Mode Multifunction Filter Based on Dual Output Current Controlled Conveyors," AEU International Journal of Electronics and Communications, Vol. 61, No. 8, 2007, pp. 528-533.

[7] J. W. Horng, C. L. Hou, C. M. Chang and W. Y. Chung, "Voltage Mode Universal Biquadratic Filters with One Input and Five Outputs," Analog Integrated Circuits and Signal Processing, Vol. 47, No. 1, 2006, pp. 73-83.

[8] O. Cicekoglu and H. Kuntman, "A New Four Terminal Floating Nullor Base Single-Input Three-Output CurrentMode Multifunction Filter," Microelectronics Journal, Vol. 30, No. 2, 1999, pp. 115-118.

[9] D. R. Bhaskar, V. K. Sharma, M. Monis and S. M. I. Rizvi, "New Current Mode Universal Biquad Filter," Microelectronics Journal, Vol. 30, No. 9, 1999, pp. 837-839.

[10] A. Fabre and M. Alami, "Universal Current Mode Biquad Implemented from Two Second Generation Current Conveyors," IEEE Transactions on Circuits Systems-I, Vol. 42, No. 7, 1995, pp. 383-385.

[11] A. Fabre, F. Dayoub, L. Duruisseau and M. Kamoun, "High Input Impedance Insensitive Second-Order Filters Implemented from Current Conveyors," IEEE Transactions on Circuits Systems-I, Vol. 41, No. 12, 1994, pp. 918-921.

[12] I. A. Khan and M. H. Zaidi, "Multifunction Translinear-C
Current Mode Filter," International Journal of Electronics, Vol. 87, No. 6, 2000, pp. 1047-1051.

[13] S. Maheshwari and I. A. Khan, "Novel Cascadable Current-Mode Translinear-C Universal Filter," Active and Passive Electronic Components, Vol. 27, No. 4, 2004, pp. 215-218.

[14] A. Toker, O. Cicekoglu, S. Ozacan and H. Kuntman, "High Output Impedance Transadmittance Type Continuous Time Multifunction Filter with Minimum Active Elements," International Journal of Electronics, Vol. 88, No. 10, 2001, pp. 1085-1091.

[15] N. A. Shah, S. Z. Iqbal and B. Parveen, "SITO High Output Impedance Transadmittance Filter Using FTFNs," Analog Integrated Circuits and Signal Processing, Vol. 40, No. 4, 2004, pp. 87-89.

[16] U. Cam, "A New Transadmittance Type First-Order All Pass Filter Employing Single Third Generation Current Conveyor," Analog Integrated Circuits and Signal Processing, Vol. 43, No. 1, 2005, pp. 97-99.

[17] N. A. Shah, S. Z. Iqbal and B. Parveen, "Lowpass and Bandpass Transadmittance Filter Using Operational Amplifier Pole," AEU International Journal of Electronics and Communications, Vol. 59, No. 7, 2005, pp. 410-412.

[18] N. A. Shah, M. Quadri and S. Z. Iqbal, "CDTA Based Universal Transadmittance Filter," Analog Integrated Circuits and Signal Processing, Vol. 52, No. 1-2, 2007, pp. 65-69.

[19] E. Altuntas and A. Toker, "Realization of Voltage and Current Mode KHN Biquad Using CCCIIs," AEU International Journal of Electronics and Communications, Vol. 56, No. 1, 2002, pp. 45-49.

[20] S. I. Liu, "High Input Impedance Filter with Low Component Spread Using Current Feedback Amplifiers," Electronics Letters, Vol. 31, No. 13, 1995, pp. 10421043.

[21] E. S. Erdogan, R. O. Topaloglu, H. Kuntman and O. Cicekoglu, "New Current Mode Special Function Continuous-Time Active Filters Employing only OTAs and OPAMPs," International Journal of Electronics, Vol. 91, No. 6, 2004, pp. 345-359. 